\title{
BIOMIMIKRI GERAK ADAPTIF TUMBUHAN MIMOSA SEBAGAI FASAD KINETIK
}

\author{
Gustav Anandhita \\ *) Corresponding author email : anandhita.gustav@unika.ac.id \\ Prodi Arsitektur, Fakultas Arsitektur dan Desain, Univeristas Katolik Soegijapranata. \\ Jl. Pawiyatan Luhur Sel. IV No.1, Bendan Duwur, Kota Semarang
}

Article info

MODUL vol 20 no 2, issues period 2020

Doi $\quad: 10.14710 / \mathrm{mdl} .20 .2 .2020 .145-150$

Received : 22 november 2020

Revised : 6 desember 2020

Accepted : 14 desember 2020

\begin{abstract}
Biomimikri merupakan metode penyelesaian masalah dengan menduplikasi desain, proses dan perilaku mahluk hidup di alam. Pada penelitian ini proses biomimikri mengambil inspirasi dari tumbuhan genus Mimosa dari keluarga Fabaceae, yang memiliki karakteristik daun yang dapat mengatup atau yang disebut sebagai gerak niktinasti. Penelitian ini bertujuan memperoleh desain arsitektural fasad bangunan dan mengetahui kemampuannya dalam mereduksi tingkat radiasi pada kulit bangunan. . Untuk mencapai tujuan tersebut, metode penelitian menggunakan mix-methods dari biomimicry thinking. Pertama, penelitian terhadap karakteristik bentuk, respon tumbuhan terhadap suhu serta cahaya, dan mekanisme gerak buka tutup daun tumbuhan genus Mimosa. Kedua, melakukan reinterpretasi desain tumbuhan Mimosa sebagai fasad kinetik menggunakan metode generative model menggunakan GH+Rhino. Ketiga, membuat simulasi untuk analisis radiasi matahari menggunakan Ladybug untuk mengetahui efek dari mekanisme buka tutup fasad kinetik tersebut terhadap nilai radiasi total yang diterima bangunan . Dari hasil analisis diketahui bahwa kinerja fasad kinetik tersebut mampu mengurangi radiasi matahari pada bangunan sampai dengan $26.3 \%$.
\end{abstract}

Keywords: biomimikri; Mimosa; fasad kinetik

\section{LATAR BELAKANG}

Para filsuf Yunani kuno telah melihat alam dan organisme yang tinggal di dalamnya sebagai model ideal bagi keseimbangan, harmoni dan keindahan yang dapat menjadi inspirasi manusia dalam mendesain. Upaya meniru mahluk hidup tersebut dalam bahasa yunani dikenal sebagai biomimikri, bios (kehidupan) dan

Gustav Anandhita mimesis (meniru). Biomimikri memiliki tujuan meniru kejeniusan desain alam untuk menciptakanan lingkungan hidup yang lebih sustainable (Benyus dalam Amer, 2019). Dalam perkembangannya, studi terhadap biomimikri tidak hanya terbatas pada peniruan bentuk desain tetapi juga proses dan sistem yang bekerja pada organisme yang ditiru. Terdapat tiga level penerapan biomimikri, yaitu level organisme, perilaku (behavior) dan ekosistem (Alshami, 2015). Biomimikri level organisme diketahui sudah dilakukan sejak era arsitektur yunani kuno, proses perancangan seringkali diilhami oleh teori proporsi golden ratio yang banyak ditemukan pada organisme di alam, baik pada bentuk hewan maupun tumbuhan. Sedangkan studi biomimikri di level behavior baru berkembang beberapa dekade terakhir. Secara garis besar terdapat dua penerapan level behavior pada arsitektur biomimikri, yaitu sistem pasif dan aktif. Beijing National Stadium dan Eastgate Center menjadi contoh penerapan biomimikri di level behavior secara pasif. Kedua desain bangunan tersebut berhasil meniru sistem penghawaan yang bekerja pada sarang burung dan rumah rayap (Radwan, 2016). Sedangkan untuk sistem aktif, pergerakan yang diperlihatkan oleh organisme tersebut juga dicoba untuk ditiru. Sebagai contoh adalah instalasi Bloom karya Doris Kim Sung, One Ocean Thematic Pavilion karya SOMA, HygroskinMeteorosensitive karya Achim Menges serta Building Media-TIC karya Enric Ruiz Geli. Yang menarik keempatnya mencoba meniru perilaku adaptif tumbuhan saat merespon perubahan lingkungan di sekitarnya. (Lopez dkk, 2016). Sifat adaptif atau kemampuan beradaptasi tersebut merupakan kunci penting dalam proses evolusi. Dihadapkan dengan perubahan lingkungan yang terus menerus, organisme dipaksa untuk menyesuikan diri dengan habitatnya agar dapat bertahan hidup dan tidak punah. Dalam penelitian ini, perilaku adaptif dari tumbuhan Mimosa akan dikaji. Tumbuhan Mimosa memiliki kemampuan gerak niktinasti, yaitu kemampuan daun merespon perubahan suhu dan cahaya. Akan tetapi pengaplikasian tumbuhan mimosa sebagai fasad gedung belum pernah diteliti sebelumnya. Melihat potensi tersebut, penelitian ini bertujuan untuk memperoleh desain arsitektural fasad bangunan yang dapat merespon intensitas cahaya dan 
perubahan posisi matahari. Dengan mengaplikasikan gerak niktinasti Mimosa pada desain fasad bangunan akan mampu membantu mengurangi tingkat radiasi matahari pada kulit bangunan.

\section{KAJIAN TEORI \\ Biomimikri}

Istilah biomimikri pertama kali dikenalkan oleh Otto Schmitt pada tahun 1982 dan dipopulerkan kembali oleh Janine Benyus pada tahun 1997 dengan mendirikan Biomimicry Institute (Amer, 2019). Tetapi usaha ilmuwan meniru sistem yang ada pada mahluk hidup lain juga sudah dilakukan sejak tahun 1482. Leonardo Da Vinci diketahui sebagai desainer pertama yang meniru sistem gerak pada sayap burung untuk menciptakan mesin terbang atau ornithopter. Studi biomimikri Leonardo Da Vinci mencakup penelitian anatomi sayap burung dan analisis distribusi udara pada bulu burung. (Couceiro, 2009). Biomimikri memiliki definisi meniru atau memimesis. Biomimikri memungkinkan adanya implementasi suatu sistem alam ke dalam sebuah desain untuk menyelesaikan permasalahan manusia. Metode biomimikri mampu menciptakan inovasi yang menggunakan standar ekologis melalui sebuah adaptasi dari objek alam seperti hewan atau tumbuhan. (Bianciardi, 2017).

Menurut Azcon dalam Lopez (2016) terdapat tiga cara melakukan transfer biologi ke arsitektur, yaitu dengan cara meniru morfologi, fungsi atau perilaku mahluk hidup. Sedangkan menurut Alshami (2015) setidaknya ada tiga level pengaplikasian biomimikri pada desain arsitektur. Pertama level organisme, yaitu meniru sebagian atau keseluruhan bentuk dari organisme. Kedua level behavior atau perilaku, yaitu meniru cara mahluk hidup merespon konteks habitat yang ada di sekitarnya. Terakhir adalah level ekosistem, dimana perancang meniru keseluruhan ekosistem yang bekerja pada suatu area.

\section{Mimosa}

Mimosa merupakan salah satu genus tumbuhan dari keluarga Fabaceae. Memiliki karakteristik morfologi berupa daun berbentuk kecil, lonjong, yang tersusun secara majemuk dan simetris. Mimosa memiliki kemampuan untuk merespon stimulus berupa cahaya dan suhu menjadi gerakan mekanik membuka dan menutup. Beberapa spesies seperti putri malu (Mimosa pudica) juga sensitif terhadap sentuhan. Anatomi tumbuhan mimosa terbagi menjadi beberapa bagian yaitu rachis (batang), pinnule (daun), pulvinule (pulvini), pulvinus, dan petiol. Dimana bagian rachis merupakan batang yang menopang daun, pulvini sebagai pangkal daun yang menempel pada rachis, pinnule merupakan ujung daun, pulvinus sebagai ujung pangkal bawah rachis dan petiol merupakan batang pada bagian bawah.

Mimosa merespon cahaya matahari dengan perubahan sudut daun. Cahaya matahari tersebut menstimulus Mimosa untuk mengaktifkan sistem turgor pada bagian pulvini. Dimana, bagian pulvini daun menggerakkan pulvinus merangsang daun untuk menutup. Gerakan menutup tersebut berurutan dari paling ujung hingga pangkal. Gerakan menutup daun Mimosa tersebut dikenal juga sebagai gerak niktinasti. Gerakan niktinasti bertujuan untuk merespon perubahan siang dan malam. Gerakan tersebut dikendalikan oleh jam biologis milik tumbuhan tersebut untuk melakukan efisiensi energi pada malam hari (Ueda, 2001). Selain itu, gerak membuka dan menutup tersebut juga dipengaruhi tingkat suhu dan cahaya sekitar. Hal ini dibuktikan daun mimosa juga menutup ketika terjadi gerhana matahari (Teguh, 2016). Bebebrapa spesies mimosa juga dapat merespon sentuhan seperti Mimosa pudica atau putri malu.

\section{Fasad Adaptif}

Fasad diambil dari bahasa latin "facies" yang berarti wajah atau penampilan. Layaknya organisme, fasad yang merupakan kulit terluar dari bangunan diharapkan juga mampu merespon perubahan lingkungan. Kemampuan beradaptasi fasad terhadap perubahan eksternal akan berdampak besar pada penghematan energi dan kenyamanan termal dalam bangunan. Studi menunjukan bahwa fasad adaptif mampu mengurangi beban pendinginan bangunan sebesar 19\% dan meningkatkan kenyamanan sampai $67.5 \%$ (Kuru, 2019). Kemampuan responsif fasad yang diperlihatkan lewat pergerakan dan perubahan bentuk secara dinamis disebut juga sebagai fasad kinetik. Terdapat beberapa bentuk transformatif fasad kinetik, antara lain tranlation, rotation, scaling dan material deformation (Moloney, 2011).

\section{METODE}

Penelitian ini bertujuan untuk memperoleh desain arsitektural fasad bangunan yang dapat merespon intensitas cahaya dan perubahan posisi matahari. Desain fasad adaptif tersebut diharapkan mampu mereduksi tingkat radiasi pada kulit bangunan. Untuk mencapai tujuan tersebut digunakan metode biomimicry thinking yang terdiri dari 4 tahapan utama yaitu Scoping, Discovering Creating, dan Evaluating (Rowland, 2013). Keempat tahapan tersebut kemudian dijabarkan sebagai berikut. Tahap pertama adalah kajian literatur dan obeservasi karakteristik bentuk, respon terhadap suhu serta cahaya, dan mekanisme gerak buka tutup daun tumbuhan genus Mimosa. Kedua, melakukan reinterpretasi gerakan niktinasti Mimosa sebagai fasad kinetik menggunakan metode generative model 
menggunakan software Rhinoceros $6+$ Grasshopper plug-in. Ketiga, membuat simulasi untuk analisis radiasi matahari menggunakan plug-in Ladybug yang terintegrasi dengan algoritma sebelumnya. Dari hasil simulasi akan diketahui efek dari mekanisme buka tutup fasad kinetik tersebut terhadap nilai radiasi total yang diterima bangunan .

\section{PEMBAHASAN}

\section{Gerak Niktinasti Mimosa}

Tumbuhan mimosa merespon paparan sinar matahari dengan cara merubah sudut pada daunnya. Perubahan sudut disebabkan adanya tekanan turgor oleh pulvini yang menyebabkan gerakan pada pulvinus. Semakin rendah tingkat cahaya matahari yang diterima permukaan daun, maka semakin besar sudut yang dihasilkan. Sehingga daun akan terlihat seperti mengatup (gambar 1).
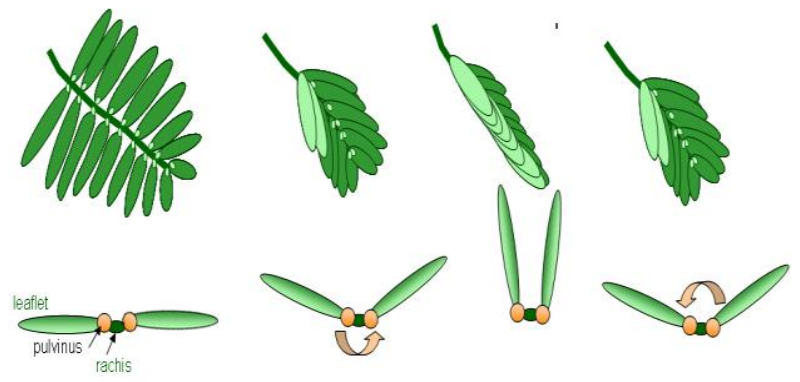

Gambar 1: Gerak niktinasti mimosa

(Sumber: https://www.quora.com/How-is-rapidplant-movement-possible)

Selain itu, perilaku gerak membuka dan menutup juga dipengaruhi oleh perubahan suhu lingkungan sekitar. Daun akan mulai menutup ketika suhu turun $1^{\circ}$ $\mathrm{C}$ dan akan kembali membuka ketika suhu sekitar naik.

\section{Generative Model}

Model fasad yang direncanakan memiliki kemampuan responsif terhadap perubahan suhu dan cahaya seperti halnya daun mimosa. Perilaku nikntinasti tersebut akan direintepretasi dengan serangkaian algoritma. Secara garis besar, algoritma pembentuk desain fasad terdiri dari 4 klaster (gambar 2). Klaster pertama berfungsi untuk membaca input data berupa lebar dan tinggi fasad pada sebuah gedung. Data tersebut kemudian akan diterjemahkan menjadi grid dengan ukuran tertentu. Ukuran grid yang dihasilkan bersifat adaptif, tergantung ukuran fasad gedung yang akan dipasang. Grid yang dihasilkan kemudian akan dibaca secara paralel oleh klaster kedua dan ketiga.

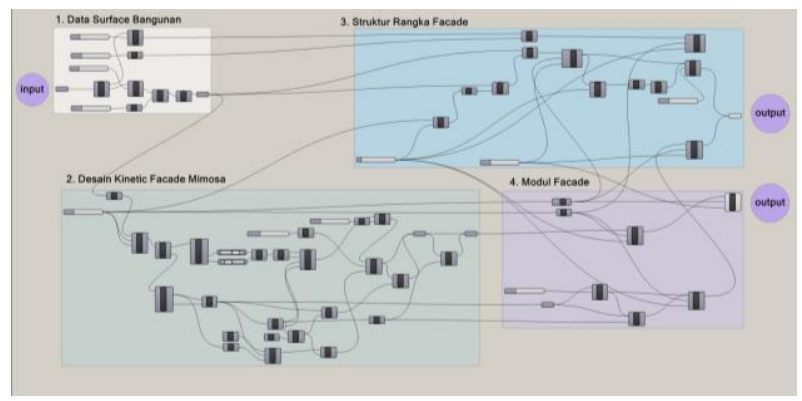

Gambar 2: Algoritma desain fasad kinetik menggunakan grasshopper di Rhino 6.0

Di dalam klaster algoritma kedua, tiap modul dalam grid akan memikri daun mimosa dalam bentuk panel fasad kinetik. Bagian yang dimimikri adalah morfologi daun dan juga perilaku gerak membuka dan menutup daun saat merespon cahaya. Saat intensitas cahaya dan suhu sekitar tinggi, maka panel akan membuka dengan sudut 0 derajat sehingga radiasi cahaya akan terhalangi. Sedangkan saat intensitas cahaya dan suhu mulai menurun, maka panel perlahan akan menutup sampai sudut 80 derajat (gambar 3).
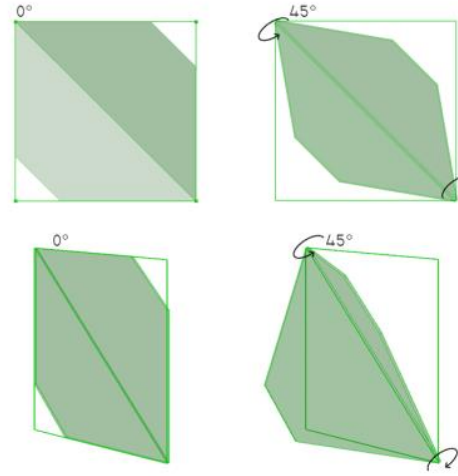
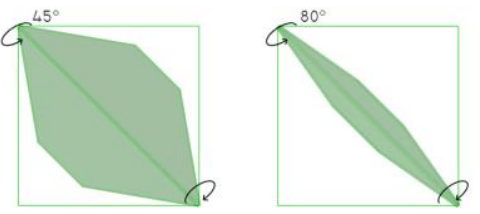

Gambar 3: Mekanisme rotasi panel sebagai mimikri gerak daun mimosa

Klaster algoritma ketiga menerjemahkan grid menjadi struktur rangka yang menempel pada permukaan bangunan. Diameter pipa rangka akan menyesuaikan berat dan lebar panel fasad kinetik di tiap modulnya. Klaster ketiga menghasilkan model rangka yang selanjutnya dapat dianalisis kekuatan rangka dalam menahan beban keseluruhan panel di tahap selanjutnya.

Terakhir, klaster algoritma keempat merupakan keseluruhan modul daun pada fasad kinetik yang menyelubungi bangunan. Luaran yang dihasilkan klaster ini dapat digunakan untuk pengembangan mekanisme dan detail purwarupa. 

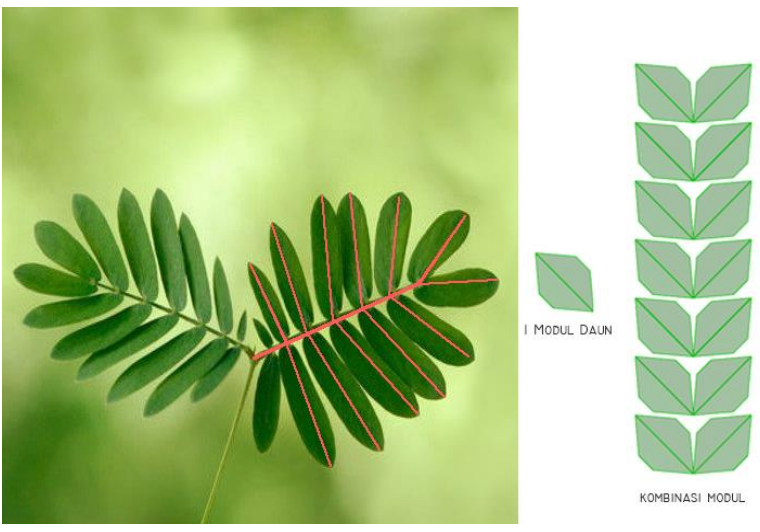

Gambar 4: Interpretasi konfigurasi daun Mimosa

\section{Mekanisme Fasad Kinetik}

Terdapat 2 level biomimikri yang akan ditiru. Yaitu level organisme dari bentuk daun mimosa, serta level behavior dari perilaku membuka dan menutup daun tersebut. Replikasi pael daun yang repetitif secara vertikal merupakan mimikri bentuk daun mimosa (gambar 4). Sedangkan transformasi rotasi servo digunakan untuk menerjemamahkan cara kerja perilaku daun mimosa tersebut (gambar 5).

Sensor yang digunakan untuk memicu transformasi panel fasad kinetik adalah sensor cahaya. Sensor akan merespon perubahan tingkat lux cahaya lingkungan. Saat sensor mendeteksi tingkat lux yang terlalu tinggi, sensor akan memberi instruksi kepada aktuator berupa servo untuk berotasi agar membuka dan menutupi permukaan bangunan. Sebaliknya ketika lux cukup rendah, sensor akan membuat fasad menutup dan membiarkan cahaya alami masuk ke dalam ruangan . Hal tersebut bertujuan agar fasad kinetik dapat mengontrol intensitas cahaya alami dalam ruangan tetap nyaman dan dalam ambang batas yang tidak berlebih (gambar 6). Dari gambar terlihat bahwa panel mampu mengurangi silau atau cahaya berlebih di dalam ruangan.
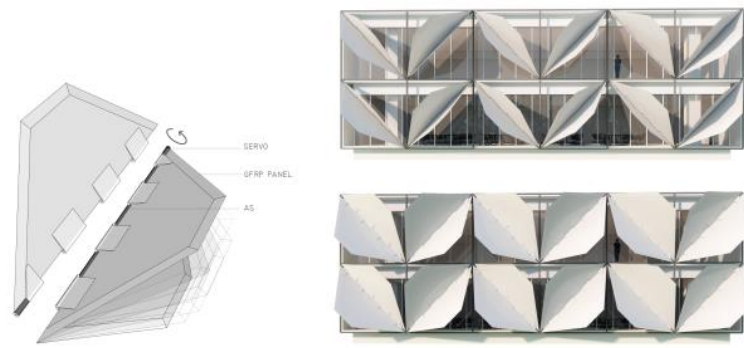

Gambar 5: Rencana mekanisme membuka dan menutup tiap modul panel (kiri). Pengaplikasian modul panel ada fasad bangunan (kanan).

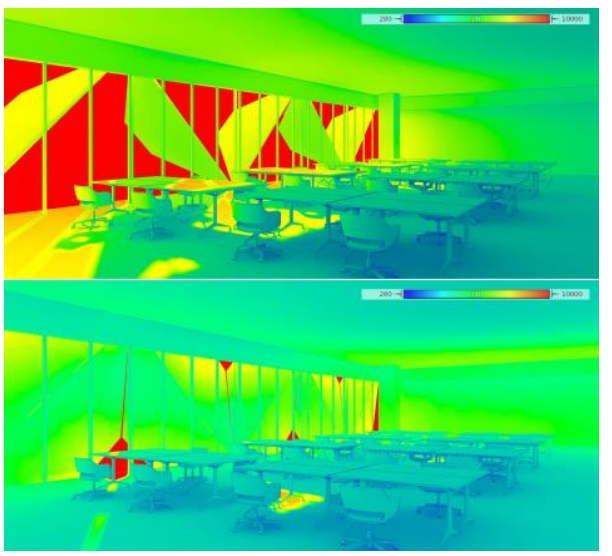

Gambar 6: Analisis glare menggunakan Enscape pada ruangan sebelum dan sesudah fasad kinetik membuka

\section{Analisis Radiasi}

Simulasi bertujuan untuk mendapatkan gambaran pengaruh fasad kinetik terhadap tingkat radiasi di dalam bangunan. Simulasi menggunakan plugin Ladybug. Bangunan yang dipilih sebagai model eksperimen adalah gedung Wisma Nusantara yang berada di Bundaran HI. Sisi bangunan yang dipasang panel berada sebelah barat (gambar 7). Waktu radiasi dipilih pukul $15.00-17.00$ WIB. Ini merupakan waktu dimana sudut matahari menyebabkan radiasi tertinggi pada fasad bangunan.. Simulasi dilakukan dengan cara membandingkan nilai radiasi saat panel masih tertutup dengan sudut rotasi 80 derajat sampai akhirnya membuka total dengan sudut 0 derajat. Lalu, tiap perubahan rotasi per 10 derajat juga akan dilihat perubahan nilai radiasi yang terjadi. Dari hasil analisis tersebut dapat diketahui efisiensi penurunan nilai radiasi yang terjadi sebelum dan sesudah (gambar 8).

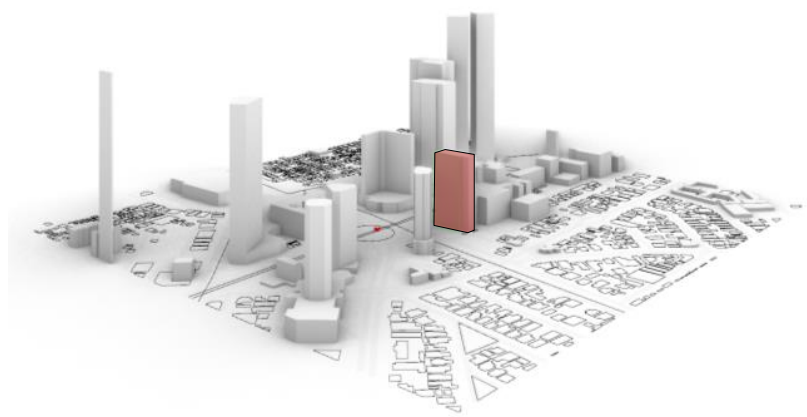

Gambar 7: Model kawasan Bundaran HI sebagai lokasi simulasi radiasi. Model menggunakan Rhino 6.0

Dari hasil simulasi (tabel 1) diketahui bahwa nilai radiasi total yang diterima bangunan semakin menurun ketika fasad mulai membuka dan menghalangi sinar matahari lanngsung yang mengenai permukaan bangunan. Data menunjukan pada gerak rotasi menutup dari 80 menuju 70,60 dan 50 terjadi penurunan nilai radiasi yang stabil per 3\%, yaitu 2,9\%, 5,3\% dan $8.5 \%$. 
Lalu penurunan radiasi terjadi secara drastis ketika panel mulai rotasi 40 derajat dan 30 derajat yaitu menjadi 14,6 $\%$ dan $19,2 \%$. Artinya terjadi efisiensi $6 \%$ dari yang awalnya hanya $3 \%$ per 10 derajat. Setelah itu penurunan radiasi kurang signifikan hanya turun $2 \%$ per 10 derajat. Total penurunan angka radiasi dari kondisi awal sampai panel membuka di sudut 0 derajat adalah $26.3 \%$ dari nilai radiasi awal (tabel 1).

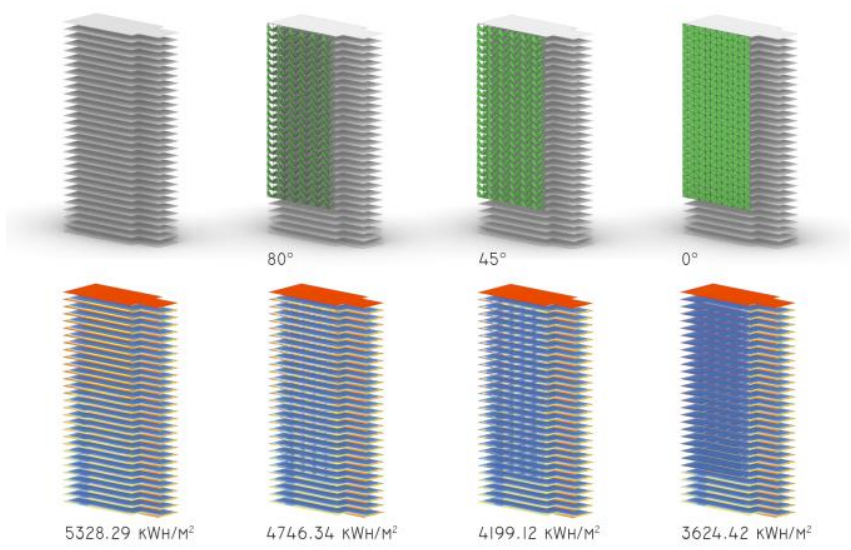

Gambar 8: Proses simulasi saat daun masih menutup dan kemudian membuka (atas). Ilustrasi nilai radiasi yang diterima bangunan (bawah). Simulasi menggunakan Ladybug

Tabel 1: Hasil simulasi radiasi sebelum dan sesudah fasad kinetik membuka.

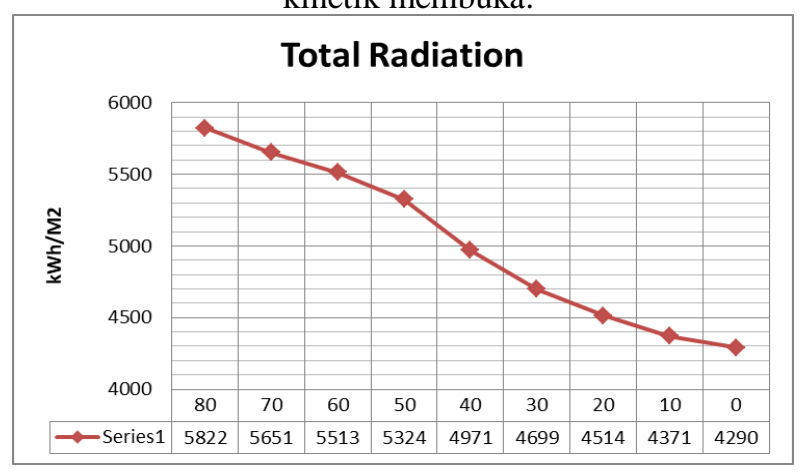

Dari diagram diatas juga dapat diketahui bahwa kinerja paling optimal dari fasad ditunjukan pada rotasi fasad $50^{\circ}$ sampai dengan $30^{\circ}$. Selanjutya penurunan nilai radiasi yang disebabkan oleh rotasi fasad kinetik tidak lagi terjadi secara signifikan. Hal ini disebabkan oleh desain fasad kinetik yang dibuat secara diagonal. Dimana hal ini menyebabkan pembayangan di sudut tertentu tidak lagi optimal. Untuk mengoptimalkan kualitas pembayangan maka desain dapat dibuat dengan kemiringan mendekati arah horisontal.

\section{KESIMPULAN}

Biomimikri terhadap tumbuhan genus Mimosa dapat dilakukan di level perilaku (behavior). Gerak niktinasti tanaman tersebut dapat diimplementasikan sebagai inspirasi fasad kinetik. Dengan menggunakan algoritma model generatif, perilaku Mimosa tersebut dapat direintepretasi menjadi fasad kinetik yang dapat merespon perubahan nilai radiasi dan sudut matahari. Hasil simulasi radiasi total menggunakan software Rhino $6.0+\mathrm{GH}+$ Ladybug dari model generatif tersebut menunjukan bahwa desain fasad yang dihasilkan mampu mereduksi nilai radiasi total sebesar $26.3 \%$ dari nilai awal.

\section{DAFTAR PUSTAKA}

Alshami, Mohammad (2015) Parametric Patterns Inspired by Nature for Responsive Building Facade. International Journal of Innovative Research in Science, Engineering and Technology vol 4 no 9 pp 8009-8019

Amer, Nihal. (2019) Biomimetic Approach in Architectural Education: Case study of 'Biomimicry in Architecture' Course. Ain Shams Engineering Journal vol 10 no 3 pp 499-506

Bianciardi Alessandro, Credi Caterina, Levi Marinella, Rosa Francesco, and Zecca Alessandro (2017) Biomimicry thinking: methodological improvements and practical implementation. Bioinspired, Biomimetic and Nanobiomaterials vol 6 no 2, pp 87-101

Couciero, Micael (2010) Application of fractional algorithms in the control of a robotic bird. Communications in Nonlinear Science and Numerical Simulation Vol 15 pp. 895-910

Kuru, Aysu, Oldfield, Philip, Bonser, Stephen, Fiorito, Francesco (2019) Biomimetic adaptive building skins: Energy and environmental regulation in buildings. Energy \& Buildings vol 205

Lopez, Marlen dkk (2015) How plants inspire façades. From plants to architecture: Biomimetic principles for the development of adaptive architectural envelopes. Renewable and Sustainable Energy Reviews vol 67 pp 692-703

Moloney, Jules. (2009) A morphology of pattern for kinetic facades. Joining Languages, Cultures and Visions. CAAD Futures pp. 200-213

Radwan, Gehan \& Osama, Nouran (2016) Biomimicry, An Approach, For Energy Effecient Building Skin Design. Procedia Environmental Sciences vol 34 pp. 178 - 189

Rowland, Regina (2017) Biomimicry step-by-step. Bioinspired, Biomimetic and Nanobiomaterials. Volume 6 Issue 2 pp. 102-112

Teguh, Rony dkk. (2016) Pemantauan Perilaku Tumbuhan Mimosa Pudica Terhadap Efek 
Gerhana Matahari Total Berbasis Wireless Smart Sensor. jurnal teknologi informasi jurnal keilmuan dan aplikasi bidang teknik informatika vol. 10 no. 2

Ueda, Minoru (2001) Molecular Approach to the Nyctinastic Movement of the Plant Controlled by a Biological Clock. Int. J. Mol. Sci. vol 2 no 4, pp156-164 